\title{
The changing profile of cutaneous leishmaniasis agent in a central province of Iran
}

\author{
GILDA ESLAMI ${ }^{1,2^{*}}$, HOSSEIN ANVARI ${ }^{1}$, MOHSEN EBADI ${ }^{1}$, YASAMIN NABIPOUR $^{1}$, FARZANEH MIRZAEI ${ }^{2}$ and \\ MOSTAFA GHOLAMREZAEI ${ }^{2}$ and ALI KHAMESIPOUR ${ }^{3}$ \\ ${ }^{1}$ Department of Parasitology and Mycology, School of Medicine, Shahid Sadoughi University of Medical \\ Sciences, Daneshjoo Blv, 638, Yazd, Iran \\ ${ }^{2}$ Research Centre of Molecular Science and Biotechnology, Shahid Sadoughi University of Medical Sciences, \\ Yazd, Iran \\ 3Center for Research and Training in Skin Diseases and Leprosy, Tehran University of Medical Sciences, Tehran, \\ Iran
}

\begin{abstract}
Cutaneous leishmaniasis in Iran is usually caused by Leishmania major or L. tropica. However, the direct examination or the cultures of biopsies for diagnosis are not very sensitive. The objective of this study was to identify the responsible species obtained from patients suspected of cutaneous leishmaniasis referred to the reference laboratory at Yazd in Iran during 2010-2011 using parasitological and molecular assays. After completing a clinical/epidemiologic data questionnaire for 145 patients with suspected skin lesions, scraping samples were collected. Each specimen was examined using both direct microscopy and molecular assay using polymerase chain reaction-restriction length polymorphism (PCR-RFLP). Location of the lesions included $47.7 \%$ on hands, $30.7 \%$ on face, $15.4 \%$ on feet, and the remainder on other regions. Out of 145 samples, Leishman body was observed in 52 by direct smear and 73 by PCR assay. Molecular assay indicated 36 cases as L. major, 36 cases as L. tropica and one case as unknown. In conclusion, molecular characterization showed changing profile of Leishmania species in the study area which may have implications on treatment and/or control strategies.
\end{abstract}

Key words: cutaneous leishmaniasis, Leishmania major, Leishmania tropica, identification, PCR, Iran

\section{Introduction}

Leishmaniasis is caused by more than 20 species of Leishmania, and is a geographicallywidespread severe disease. It includes visceral leishmaniasis (VL), cutaneous leishmaniasis $(C L)$, and mucocutaneous leishmaniasis (Herwaldt, 1999). It is estimated that 350 million people are at risk in 88 countries, with a global incidence of 1-1.5 million cases of cutaneous and 500,000 cases of visceral leishmaniasis (Desjeux, 2001; Dujardin, 2006). Cutaneous leishmaniasis is usually caused by Leishmania mexicana and Leishmania braziliensis complex in the New World, and by Leishmania major, Leishmania tropica and Leishmania aetiopica complex in the Old World. About 90\% of cases occur in Afghanistan, Algeria, Iran, Iraq, Saudi Arabia, Syria, Brazil, and Peru (Scarisbrick et al., 2006). In Iran, the causative agents of anthroponotic and zoonotic CL are $L$. tropica and L. major, respectively (Nadim \& Faghih, 1968). One of the important endemic foci in Iran is Yazd Province. Cutaneous leishmaniasis is a clinically polymorphic disease, its manifestations ranging from asymptomatic infection to benign self-limited cutaneous ulcer or to more protracted and extensive lesions (Masmoudi et al., 2007). This clinical polymorphism may result from variability either in the host immune response or in the parasite pathogenic diversity. This heterogeneity is thought to result in gradual accumulation of divergent mutations, sexual recombination (Nolder et al., 2007; Ravel et al., 2006), genetic exchange and hybridization (Jenni et al., 1986; Gaunt et al., 2003).

Diagnosis of $\mathrm{CL}$ is critical because of the high cost and significant toxicity of current treatment regimens (Vega-Lopez, 2003). Also, for both clinical and epidemiological reasons, it is important to identify the species of Leishmania in each region. Although various species require distinct management approaches, different species of Leishmania can cause similarly-appearing

\footnotetext{
*Correspondence: Gilda Eslami; E-mail address: eslami_g2000@yahoo.com; g_eslami@ssu.ac.ir
} 
cutaneous lesions in the same geographical region. Unfortunately, the conventional diagnostic techniques for $\mathrm{CL}$ have some limitations. Microscopic examinations are rapid and cheap, but they have low sensitivity particularly in chronic lesions (Chargui et al., 2005). While cultures of Leishmania are more sensitive, they are susceptible to microbiological contamination and are difficult due to particular growth requirements of different strains (Dilmec et al., 2008). Furthermore, some strains grow better than others in vitro, and this fact causes selective growth of dominant strains during culture in mixed infections (Minodier et al., 1997). Currently, L. tropica is considered the predominant species in Iran. Molecular techniques, such as polymerase chain reaction $(P C R)$, permit precise identification and characterization of parasites in isolates obtained from patients (Marfurt et al., 2003; Bensoussan et al., 2006). Of all molecular methods used for species determination, PCR-RFLP is proved to be the most sensitive and specific technique (de Oliveira et al., 2003; Culha et al., 2006). Skin biopsy and also materials obtained by skin scrape/exudate have been used for PCR in different studies (Laskay et al., 1995). The objective of this study was therefore to identify and molecular characterize the parasites responsible for $C L$ in endemic area of Yazd, Iran, using PCR-RFLP.

\section{Materials and Methods}

\section{Study area and subjects}

This study was restricted to Yazd, the capital of the province of Yazd at the central of Iran. The study was conducted during 2010 to 2011. A total of 145 patients clinically suspected of CL and referred by dermatologists to the reference central laboratory and Nikoupoor clinic laboratory of Yazd, Iran for confirmation were examined. The skin lesions showed different clinical morphologic manifestations ranging from an erythematous nodule to ulcerated lesions to nodular, nodulo-ulcerative, and non-ulcerative diffuse types with or without crusting. A clinical questionnaire was used to collect information on site of lesion, duration of its development, and geographical location of the patient's house.

\section{Isolation and parasite examination}

Two microscopic smears were taken from each patient by scraping of the raised internal border of skin lesions by an experienced parasitologist. One smear was used for molecular assay, and the other was methanol-fixed in and stained with Giemsa for microscopic examination. Three reference strains were used as control in the molecular study, the Iranian reference strain of $L$. major (MRHO/IR/75/ER), L. tropica (MHOM/IR/99/YAZ1), and L. infantum (MCAN/IR/97/LON49).

All of the unstained slides were soaked in sterile phosphate-buffered saline (PBS; $\mathrm{pH}=7.4$ ). The samples were completely removed aseptically with surgical blades and transferred to a sterile $1.5 \mathrm{~mL}$ microtube (El Tai et al., 2001), washed 3 times with sterile PBS, and centrifuged at $3000 \mathrm{rpm}$ for 5 minutes at room temperature. Then the pellets were resuspended in $200 \mu \mathrm{L}$ of TE (10 mM Tris, $1 \mathrm{mM}$ EDTA, $\mathrm{pH}=8.0$ ), $200 \mu \mathrm{L}$ of binding buffer, and $20 \mu \mathrm{L}$ of proteinase $\mathrm{K}$, and were incubated either at $72^{\circ} \mathrm{C}$ for 2 hours or at $56^{\circ} \mathrm{C}$ overnight. Finally, all DNA extractions were conducted using the High Pure PCR Template Preparation Kit (Cat. No. 11796828001; Roche, Germany) as recommended by the manufacturer. Extracted DNA was assessed by gel agarose electrophoresis and spectrophotometer, and then was stored at $4^{\circ} \mathrm{C}$ for further work.

Small subunit (SSU) ribosomal RNA ( $\mathrm{rRNA}$ ) and $5.8 \mathrm{~S}$ rRNA regions that are related to ribosomal ITS1 were amplified using the primers LITSr (5'-CTGGATCATTTTCCGATG-3') and L5.8s (5'TGATACCACTTATCGCACTT-3') (Davila \& Momen, 2000). Amplification of the DNA was performed in a $50-\mu \mathrm{L}$ reaction tube containing $0.2 \mathrm{mM}$ deoxyribonucleotide triphosphates (dNTPs) mix, $1.5 \mathrm{mM} \mathrm{MgCl}_{2}, 1 \mathrm{U}$ of Taq DNA polymerase (Fermentas, Leon-Rot, Germany), $10 \mathrm{pmol}$ of each primer, and 100-100ong of extracted DNA obtained from isolates. Amplification stages were as follows in an Eppendorf (Eppendorf, Germany) thermo cycler: initial denaturation at $95^{\circ} \mathrm{C}$ for 5 minutes followed by 40 cycles of denaturation at $95^{\circ} \mathrm{C}$ for 45 seconds, the annealing at $50^{\circ} \mathrm{C}$ 
for 45 seconds, and the extension at $72^{\circ} \mathrm{C}$ for 45 seconds, with an additional and final extension at $72^{\circ} \mathrm{C}$ for 5 minutes. Five microliters of PCR product were run along with a 50-base pair (bp) ladder on a $1 \%$ agarose gel containing ethidium bromide at $5 \mathrm{~V} / \mathrm{cm}$. The gel was observed on a UV transilluminator, and was evaluated in comparison with the 3 Leishmania standards (El Tai et al., 2001; Toz et al., 2009).

The PCR products were digested with restriction enzyme Haelll (Fermentas, Leon-Rot, Germany) and its related buffer at $37^{\circ} \mathrm{C}$ for 1 hour to analyze the species. Digested fragments were assessed using $2 \%$ agarose gel in 0.5 X TBE buffer and visualized through staining with ethidium bromide under a UV transilluminator (El Tai et al., 2001; Schonian et al., 2003). Samples with different pattern versus of all standards were sent for sequencing, and the results were assessed using BLAST software (Altschul et al., 1997).

\section{Results}

Among 145 isolates obtained from patients with suspected cutaneous leishmaniasis, 52 (71.2\%) and $73(100 \%)$ samples were positive for Leishman body using microscopic examination and molecular assay, respectively. Alternatively, 21 (28.8\%) of PCR-positive patients were not detected by microscopic examination. PCR-positive cases included $58.9 \%$ males and $41.1 \%$ females (Table1). PCR-negative persons comprised of $59.7 \%$ males and $40.3 \%$ females. The most common age group for both PCR-positive and PCR-negative persons was 20-29 years. The most common clinical forms of the lesion for PCR-positive and PCR-negative persons were papule and ulcer, respectively. All of the PCR-positive cases were Iranian except 13 Afghan people. The time lapse between initiation of signs and diagnosis was less than 90 days in 50 (68.5\%), 91-120 days in 9 (12.3\%), 121-150 days in 2 (2.7\%), and more than 150 days in 12 cases (16.5\%). PCR-positive patients included $61(83.6 \%)$ urban and $12(16.4 \%)$ rural residents (table1). For PCR-negative persons, 66 (91.7\%) were living in urban areas and $6(8.3 \%)$ in rural areas (Table1).

Table1: Demographic characteristics and types of clinical lesions in all samples (mean age=20-29 years)

\begin{tabular}{lllllll}
\hline PCR results & Sex N (\%) & & \multicolumn{2}{c}{ Residential Setting N (\%) } & \multicolumn{2}{l}{ Clinical lesion N (\%) } \\
\hline & Female & Male & Urban & Rural & Papule & Ulcer \\
Positive & $30(41.1 \%)$ & $43(58.9 \%)$ & $61(83.6 \%)$ & $12(16.4 \%)$ & $29(39.7 \%)$ & $44(60.3 \%)$ \\
Negative & $29(40.3 \%)$ & $43(59.7 \%)$ & $66(91.7 \%)$ & $6(8.3 \%)$ & $26(36.1 \%)$ & $46(63.9 \%)$ \\
\hline
\end{tabular}

Locations of lesions were $47.7 \%$ on the hands, $30.7 \%$ on the face, $15.4 \%$ on the feet, and the remainder in other regions. The observed lesions were in different sizes and shapes, including acute necrotizing, ulcerative, nodular, volcano-shaped, impetiginous, erysipeloid, eczematoid, verrucous, tumoral, recidivans, abortive and lupoid. The 73 positive samples were confirmed by ITS1-PCR method, in which 72 (98.6\%) cases exhibited the amplicon with 350bp in length (the presence of which confirms the genus as Leishmania), and 1 (1.4\%) sample showed apparent variability as an ITS1- PCR product size which was 10obp different from the standard specimens, since the amplicon was $450 b p$ in length (Figure 1 ).

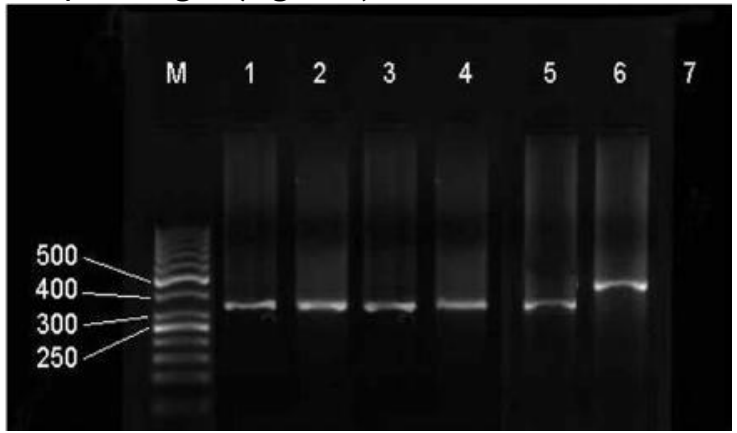

Figure 1: Electrophoresis results of ITS1-PCR from smears 
M: Molecular marker (50 bp); Lane 1: Standard Leishmania major (MRHO/IR/75/ER); Lane 2: Standard Leishmania tropica (MHOM/IR/99/YAZ1); Lane 3: Leishmania infantum (MCAN/IR/97/LON49); Lane 4,5: PCR product according to standard sample; Lane 6: PCR product with no accordance with standard sample; Lane 7: negative control

The ITS1-PCR results identified 36 (49.3\%) samples as L. major (which after digesting showed 210bp and 140bp fragments) and $36(49.3 \%)$ as L. tropica (which after digesting showed 20obp and 6obp fragments). After digesting, one (1.4\%) sample showed a different pattern versus of all standards, since it had fragments of $153 \mathrm{bp}$ and $296 \mathrm{bp}$ (Figure 2).

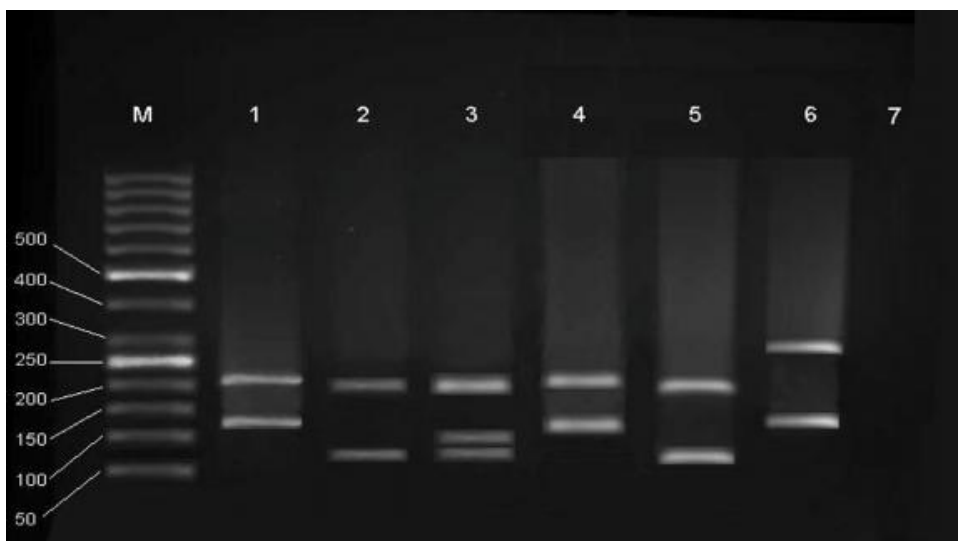

Figure 2: Restriction enzyme digestion profile of amplified ITS1 region with the restriction enzyme of HaellI

M: Molecular marker (50 bp); Lane 1: Standard Leishmania major; Lane 2: Standard L. tropica; Lane 3: Standard L. infantum; Lane 4: L. major according to standard; Lane 5: L. tropica according to standard; Lane 6: The one sample different from the normal samples and standard patterns; Lane 7: negative control

\section{Discussion}

DNA-based molecular techniques have improved the identification of Leishmania parasites at the species level (Weirather et al., 2011; Galaï et al., 2011; Parhizkari et al., 2011; Ghasemian et al., 2011; Veland et al., 2012). The differential diagnosis of species and also suitable therapeutic strategies for the disease can be determined through precise protocols for identification of isolates from endemic areas where more than one Leishmania species may be present. Treatment for Leishmania is expensive and has considerable side effects. Such information can therefore, be used for ecologic, clinical, and epidemiologic studies on Leishmania species.

In the present study, PCR amplification of ITS1 from all isolates yielded fragments of about 350 and 450bp, whereas most standard strains show a similar $350 \mathrm{bp}$ fragment (El Tai et al., 2000; Schonian et al., 2001; Rotureau et al., 2006; Toz et al., 2009). This substantial difference in the PCR product sizes directed us to sequence the mentioned PCR product. Molecular analysis by Blast software showed that the selected sequence had a close similarity with Crithidia fasciculate (97\%), and Crithidia luciliae (90\%), and a similarity of $40 \%$ with L. infantum (MCAN/IR/97/LON49). Also, it had similarity with the species found elsewhere in Iran (Doudi et al., 2010). Our results confirmed some other documents in digestion with Haelll resulted in 140bp and 220bp fragments corresponding to L. major, and 6obp and 200bp fragments corresponding to L. tropica, and also fragments of 60, 80 (Schonian et al., 2001; Schonian et al., 2003; Rotureau et al., 2006; Toz et al., 2009). In L. tropica, with regard to the restriction map of the enzyme used, 4 fragments with approximate sizes of 20,55, 64, and 200bp should be observed in this case. However, because of the small size of the first fragment (2obp) and overlapping of 2 fragments with similar molecular weights ( 55 and 64bp), we only observed 6obp and 200bp fragments for L. tropica (Toz et al., 2009).

This study showed a different identification profile compared with the report by Yaghoobi-Ershade et al. (2002) which showed that L. tropica is the dominant species. This could claim new emergence of L. major in this area. On the other hand, according to the interview 
statements, most of the subjects had history of travelling to villages around the Yazd city such as Ardekan where the dominant species is L. major (Yaghoobi-Ershadi et al., 2004). This movement of people in such areas provides the necessary circumstances, in which parasite can be introduced to non-endemic areas, leading to the emergence of new zoonotic cutaneous leishmaniasis $(Z C L)$ foci, provided that ecological conditions such as the presence of potential vectors and reservoir hosts, are in favor of the parasite lifecycle. Therefore, we could hypothesize that zoonotic cutaneous leishmaniasis had not previously been endemic in the study area. A similar changing profile has already been reported from Jahrom, another part of Iran (Davami et al., 2010).

Similar to the findings of some other studies (Yaghoobi-Ershadi et al., 2001; Fazaelia et al., 2009), the most affected part of the body was upper limb followed by the face. This is one of the usual characteristics of the zoonotic cutaneous leishmaniasis; whereas, for the anthroponotic cutaneous leishmaniasis, the most commonly involved sites are face and upper limbs (Sharma et al., 2005). However, this is not always consistent, and there are some reports indicating predominant involvement of the face in zoonotic cutaneous leishmaniasis (Talari et al., 2006; Momeni \& Aminjavaheri, 1994).

In conclusion, the emergence of $Z C L$ in Yazd is likely to have been originated from other foci around the city. To find the original source of the parasite, further studies such as genotype analysis of the Leishmania isolates in comparison with isolates from other ZCL endemic areas are required. However, further information based on a search for the L. major reservoir and hosts and/or infected Phlebotomus papatasi are needed to confirm the emergence of a new L. major in Yazd province.

\section{Acknowledgements}

The authors are thankful to the Shahid Sadoughi University of Medical Sciences in Yazd, Iran for financial support. Dr. Seyedhossein Hekmatimoghadam, Dr. Ali Fatahi, Masoumeh Taraheni Nia and Fereshteh Askari are thanked for their kind cooperation during this study.

\section{References}

Altschul, S.F., Madden, T.L., Schäffer, A.A., Zhang, J., Zhang, Z., Miller, W. \& Lipman, D.J. (1997) Gapped BLAST and PSI-BLAST: a new generation of protein database search programs. Nucleic Acids Research 25, 3389-3402.

Bensoussan, E., Nasereddin, A., Jonas, F., Schnur, L.F. \& Jaffe, C.L. (2006) Comparison of PCR assays for diagnosis of cutaneous leishmaniasis. Journal of Clinical Microbiology 44, 14351439.

Chargui, N., Bastien, P., Kallel, K., Haouas, N., Akrout, F.M., Masmoudi, A., Zili, J., Chaker, E., Othman, A.D., Azaiez, R., Crobu, L., Mezhoud, H. \& Babba, H. (2005) Usefulness of PCR in the diagnosis of cutaneous leishmaniasis in Tunisia. Transactions of the Royal Society of Tropical Medicine and Hygiene 99, 762-768.

Culha, G., Uzun, S., Ozcan, K., Memisoglu, H.R. \& Chang, K.P. (2006) Comparison of conventional and polymerase chain reaction diagnostic techniques for leishmaniasis in the endemic region of Adana, Turkey. International Journal of Dermatology 45, 569-572.

Davami, M.H., Motazedian, M.H. \& Sarkari, B. (2010) The changing profile of cutaneous leishmaniasis in a focus of the disease in Jahrom district, southern Iran. Annals of Tropical Medicine and Parasitology 104, 377-382.

Davila, A.M. \& R., Momen, H. (2000) Internal-transcribed-spacer (ITS) sequences used to explore phylogenetic relationships within Leishmania. Annals of Tropical Medicine and Parasitology 94, 651-654. 
De, Oliveira, C.I., Báfica, A., Oliveira, F., Favali, C.B., Correa, T., Freitas, L.A., Nascimento, E., Costa, J.M. \& Barral, A. (2003) Clinical utility of polymerase chain reaction-based detection of Leishmania in the diagnosis of American cutaneous leishmaniasis. Clinical Infectious Diseases 37, e149-153.

Desjeux, P. (2001) The increase in risk factors for leishmaniasis worldwide. Transactions of the Royal Society of Tropical Medicine and Hygiene 95, 239-243.

Dilmec, F., Matur, A., Alhan, E., Uzun, S., Karakas, M., Alabaz, D., Aksoy, N., Akkafa, F., Aksaray, F. \& Memisoglu H.R. (2008) Investigation of Leishmania parasites from clinical samples using polymerase chain reaction technique in Cukurova Region, Turkey. Harran Üniversitesi Tıp Fakültesi Dergisi 5, 10-14.

Doudi, M., Seyed, Hossein, Hejazi, S.H., Razavi, M.R., Narimani, M., Khanjani, S. \& Eslami, G. (2010) Comparative molecular epidemiology of Leishmania major and Leishmania tropica by PCRRFLP technique in hyper endemic cities of Isfahan and Bam, Iran. Medical Science Monitor 16, CR530-535.

Dujardin, J.C. (2006) Risk factors in the spread of leishmaniases: towards integrated monitoring? Trends in Parasitology 22, 4-6.

El, Tai, N.O., El, Fari, M., Mauricio, I., Miles, M.A., Oskam, L., El, Safi, S.H., Presber, W.H. \& Schönian, G. (2001) Leishmania donovani: intraspecific polymorphisms of Sudanese isolates revealed by PCR-based analyses and DNA sequencing. Experimental Parasitology 97, 35-44.

El, Tai, N.O., Osman, O.F., El, Fari, M., Presber, W. \& Schönian, G. (2000) Genetic heterogeneity of ribosomal internal transcribed spacer in clinical samples of Leishmania donovani spotted on filter paper as revealed by single-strand conformation polymorphisms and sequencing. Transactions of the Royal Society of Tropical Medicine and Hygiene 94, 575-579.

Fazaelia, A., Fouladic, B. \& Sharifi, I. (2009) Emergence of cutaneous leishmaniasis in a border area at south-east of Iran: an epidemiological survey. Journal of Vector Borne Diseases 46, $36-42$.

Galaï, Y., Chabchoub, N., Ben-Abid, M., Ben-Abda, I., Ben-Alaya-Bouafif, N., Amri, F., Aoun, K. \& Bouratbine, A. (2011) Diagnosis of Mediterranean visceral leishmaniasis by detection of Leishmania antibodies and Leishmania DNA in oral fluid samples collected using an Oracol device. Journal of Clinical Microbiology 49, 3150-3153.

Gaunt, M.W., Yeo, M., Frame, I.A., Stothard, J.R., Carrasco, H.J., Taylor, M.C., Mena, S.S., Veazey, P., Miles, G.A., Acosta, N., de, Arias, A.R. \& Miles, M.A. (2003) Mechanism of genetic exchange in American trypanosomes. Nature 421, 936-939.

Ghasemian, M., Maraghi, S., Samarbafzadeh, A.R., Jelowdar, A. \& Kalantari, M. (2011) The PCRbased detection and identification of the parasites causing human cutaneous leishmaniasis in the Iranian city of Ahvaz. Annals of Tropical Medicine and Parasitology 105, 209-215.

Herwaldt, B.L. (1999) Leishmaniasis. Lancet 354, 1191-1199.

Jenni, L., Marti, S., Schweizer, J., Betschart, B., Le Page, R.W., Wells, J.M., Tait, A., Paindavoine, P., Pays, E. \& Steinert, M. (1986) Hybrid formation between African trypanosomes during cyclical transmission. Nature 322, 173-175.

Laskay, T., Mikó, T., L., Negesse, Y., Solbach, W., Röllinghoff, M., Frommel, D. (1995) Detection of cutaneous Leishmania infection in paraffin-embedded skin biopsies using the polymerase chain reaction. Trans $R$ Soc Trop Med Hyg 89 (3): 273-5.

Marfurt, J., Nasereddin, A., Niederwieser, I., Jaffe, C., L., Beck, H.P. \& Felger, I. (2003) Identification and differentiation of Leishmania species in clinical samples by PCR amplification of the miniexon sequence and subsequent restriction fragment length polymorphism analysis. Journal of Clinical Microbiology 41, 3147-3153. 
Masmoudi, A., Ayadi, N., Boudaya, S., Meziou, T.J., Mseddi, M., Marrekchi, S., Bouassida, S., Turki, H. \& Zahaf, A. (2007) Clinical polymorphism of cutaneous leishmaniasis in centre and south of Tunisia. Bulletin de la Société de Pathologie Exotique 100, 36-40.

Minodier, P., Piarroux, R., Gambarelli, F., Joblet, C. \& Dumon, H. (1997) Rapid identification of causative species in patients with Old World leishmaniasis. Journal of Clinical Microbiology 35, 2551-2555.

Momeni, A.Z. \& Aminjavaheri, M. (1994) Clinical picture of cutaneous leishmaniasis in Isfahan, Iran. International Journal of Dermatology 33, 260-265.

Nadim, A. \& Faghih, M. (1968) The epidemiology of cutaneous leishmaniasis in the Isfahan province of Iran. I. The reservoir. II. The human disease. Transactions of the Royal Society of Tropical Medicine and Hygiene 62, 534-542.

Nolder, D., Roncal, N., Davies, C.R., Llanos-Cuentas, A., Miles, M.A. (2007) Multiple hybrid genotypes of Leishmania (viannia) in a focus of mucocutaneous Leishmaniasis. American Journal of Tropical Medicine and Hygiene 76, 573-578.

Parhizkari, M., Motazedian, M.H., Asqari, Q. \& Mehrabani, D. (2011) The PCR-based detection of Leishmania major in Mus musculus and other rodents caught in southern Iran: a guide to sample selection. Annals of Tropical Medicine and Parasitology 105, 319-323.

Ravel, C., Cortes, S., Pratlong, F., Morio, F., Dedet, J.P. \& Campino, L. (2006) First report of genetic hybrids between two very divergent Leishmania species: Leishmania infantum and Leishmania major. International Journal of Parasitology 36, 1383-1388.

Rotureau, B., Ravel, C., Couppié, P., Pratlong, F., Nacher, M., Dedet, J., P. \& Carme, B. (2006) Use of PCR-restriction fragment length polymorphism analysis to identify the main new world Leishmania species and analyze their taxonomic properties and polymorphism by application of the assay to clinical samples. Journal of Clinical Microbiology 44, 459-467.

Scarisbrick, J.J., Chiodini, P.L., Watson, J., Moody, A., Armstrong, M., Lockwood, D., Bryceson, A. \& Vega-López, F. (2006) Clinical features and diagnosis of 42 travellers with cutaneous leishmaniasis. Travel Medicine and Infectious Disease 4(1):14-21.

Sharma, N.L., Mahajan, V.K., Kanga, A., Sood, A., Katoch, V.M., Mauricio, I., Singh, C.D., Parwan, U.C., Sharma, V.K. \& Sharma, R., C. (2005) Localized cutaneous leishmaniasis due to Leishmania donovani and Leishmania tropica: preliminary findings of the study of $161 \mathrm{new}$ cases from a new endemic focus in Himachal Pradesh, India. American Journal of Tropical Medicine and Hygiene 72, 819-824.

Schonian, G., Nasereddin, A., Dinse, N., Schweynoch, C., Schallig, H., D., Presber, W., Jaffe, C., L. (2003) PCR diagnosis and characterization of Leishmania in local and imported clinical samples. Diagnostic Microbiology and Infectious Disease 47: 349-58.

Schonian, G., Schnur, L., el Fari, M., Oskam, L., Kolesnikov, A.A., Sokolowska-Köhler, W. \& Presber, W. (2001) Genetic heterogeneity in the species Leishmania tropica revealed by different PCR-based methods. Transactions of the Royal Society of Tropical Medicine and Hygiene 95, 217-224.

Talari, S.A., Talaei, R., Shajari, G., Vakili, Z. \& Taghaviardakani, A. (2006) Childhood cutaneous leishmaniasis: report of 117 cases from Iran. Korean Journal of Parasitology 44, 355-360.

Toz, S.O., Nasereddin, A., Ozbel, Y., Ertabaklar, H., Culha, G., Sevil, N., Ziya, Alkan, M. \& Jaffe, C.L. (2009) Leishmaniasis in Turkey: molecular characterization of Leishmania from human and canine clinical samples. Tropical Medicine and International Health 14, 1401-1406.

Vega-lopez, F. (2003) Diagnosis of cutaneous leishmaniasis. Current Opinion in Infectious Diseases 16, 97-101.

Veland, N., Boggild, A.K., Valencia, C., Valencia, B.M., Llanos-Cuentas, A., Van, der, Auwera, G., Dujardin, J.C. \& Arevalo, J. (2012) Leishmania (Viannia) species identification on clinical samples from cutaneous leishmaniasis in Peru: assessment of a molecular step-wise approach. Journal of Clinical Microbiology 50, 495-498. 
Weirather, J.L., Jeronimo, S.M., Gautam, S., Sundar, S., Kang, M., Kurtz, M.A., Haque, R., Schriefer, A., Talhari, S., Carvalho, E.M., Donelson, J.E. \& Wilson, M.E. (2011) Serial Quantitative PCR Assay for Detection, Species Discrimination, and Quantification of Leishmania spp. in Human Samples. Journal of Clinical Microbiology 49, 3892-3904.

Yaghoobi-Ershadi, M.R., Hanafi-Bojd, A.A., Akhavan, A.A., Zahrai-Ramazani, A.R. \& Mohebali, M. (2001) Epidemiological study in a new focus of cutaneous leishmaniosis due to Leishmania major in Ardestan town, central Iran. Acta Tropica 79, 115-121.

Yaghoobi-Ershadi, M.R., Jafari, R. \& Hanafi-Bojd, A.A. (2004) A new epidemic focus of zoonotic cutaneous leishmaniasis in central Iran. Annals of Saudi Medicine 24, 98-101. 